\title{
Case and agreement in Cupeño: Morphology obscures a simple syntax
}

\author{
Theodore LeVin \& Ryo Masuda \\ Massachusetts Institute of Technology*
}

\section{Introduction}

Cupeño is an extinct Uto-Aztecan language that was spoken by the Cupeño people in Southern California. It is part of the Takic group, and forms the Cupan subdivision together with Luiseño, Juaneño, and Cahuilla spoken in geographically neighboring regions. The data discussed in this paper are taken from Hill's (2005) grammar, which contains data from her own fieldwork during 1962-1963 as well as field notes from previous work by Paul-Louis Faye, collected in the 1920s. The annotation H\#\# denotes the page from which the example was taken.

Among the Uto-Aztecan languages, Cupeño is unique in that it has been described as displaying TAM-based split ergativity (Barragan 2003; Hill 2005). The language's case and agreement morphology patterns correlate with tense: subject clitics and subject verbal agreement are in complementary distribution. The former is only realized in non-past tense, the latter only in past tense. Subject clitics display ergative-absolutive alignment and subject agreement displays a nominative-accusative alignment. In this paper, we argue that this distribution does not arise due to variation in syntactic structure (as has been suggested elsewhere for TAM-based ergativity splits); rather, the regular output of the syntactic derivation is subject to morphological constraints that obscure the syntax of the language. Clitic and agreement morphology are both sensitive to tense specification, giving the illusion of a syntactic deviation conditioned by tense. Contrary to previous analyses, we conclude that Cupeño does not exhibit split ergativity. Rather, it exhibits a uniform tripartite case system that is reflected in its person-number clitics and consistent nominative-accusative agreement.

The paper is organized as follows. In $\S 2$ we provide an overview of the Cupeño data, identifying aspects of it which will be accounted for under our analysis. In $\S 3$ we present the morphosyntactic notions of Case assignment and $\varphi$-agreement which form the basis for our proposal and argue that Cupeño exhibits a regular syntax across tense that is then acted upon by the morphological component. In $\S 4$ we provide a counterargument against approaches which treat the Cupeño facts as arising from alternations within the narrow syntax. In $\S 5$ we sketch an implementation of our analysis in the framework of Distributed Morphology and conclude in $\S 6$.

${ }^{*}$ We thank Adam Albright, Karlos Arregi, Jessica Coon, Line Mikkelsen, David Pesetsky, and the audience at BLS40 for discussion and comments. 


\section{Overview}

The central generalization of Cupeño PN morphology is that subject marking differs between past and non-past predicates: in the past, a clitic appears in a Wackernagel clitic cluster (positioned second in the utterance) whereas in the non-past, an agreement morpheme appears affixed to the verb. ${ }^{1}$ In addition to the positional asymmetry, syntactic alignment also differs: the non-past subject-marking clitic is ergative-absolutive, while the past subjectmarking affix is nominative. In all tenses, object agreement is realized as a proclitic on the verb. On the surface, this pattern is reminiscent of the phenomenon of split-ergativity. However, in subsequent sections, we argue that such a characterization is inappropriate for Cupeño.

(1) Subject and Object PN Morphology in Cupeño

\begin{tabular}{ccc}
\hline & \multicolumn{2}{c}{ Verb } \\
\cline { 2 - 3 } & Non-past & Past \\
\hline Subject & clitic in complex, Erg-Abs & affix on verb, Nom(-Acc) \\
Object & proclitic on verb & proclitic on verb \\
\hline
\end{tabular}

The next three subsections detail the aspects of this past-nonpast asymmetry.

\subsection{Non-Past Construction: Morphology in the Clitic Complex}

Cupeño utilizes a clitic complex which appears in what is referred to as Wackernagel's position, as the second item in the utterance. Given that the clitic complex can disrupt constituents as in (2b), we can be sure that it does not (uniformly) occupy a V2 position. ${ }^{2}$

$$
\begin{aligned}
& \text { a. } \text { axwe-sh }=\text { she }=\text { qwe }=\mathbf{p} \quad \text { ne' }=\text { ne } \quad \text { isi-ly }=e \\
& \text { ODEM-NPN }=\text { dub }=\text { noni }=3 \text { sg.erg } 1 \mathrm{SG} \cdot \mathrm{PRO}=1 \mathrm{sG} \cdot \mathrm{ERG} \text { coyote- } \mathrm{NPN}=\mathrm{CF} \\
& \text { ishmivi-y } \quad n i=m a ' a \\
& \text { something-OBJ 1SG.OBJ=give.HAB } \\
& \text { 'That Coyote might give me something.' } \\
& \text { b. kanaasta }=\mathbf{k u} \text { 'ut ay'ani-sh pem-yaw-neq } \\
& \text { basket=REP big-NPN 3PL-carry-MOTC } \\
& \text { 'They came bringing a big basket.' }
\end{aligned}
$$

In non-past constructions, a subject clitic appears in the complex, and the realization of this clitic is dependent on person and number as well as transitivity of the predicate.

\footnotetext{
${ }^{1}$ Glosses: ABS: absolutive case; ACC: accusative; CF: contrastive focus; ERG: ergative; IRR: irrealis; MOTC: motion coming; NOM: nominative; NONI: non-instantiative; NPN: non-possessed noun; OBL: oblique case; R: realis REP: reportative; SS: same subject

${ }^{2}$ Items that appear in the clitic complex are broadly categorized into clitics which express evidentiality, modality, and PN agreement.
} 
(3) Non-past Subject PN Clitics in the Complex (Hill 2005:78)

\begin{tabular}{rll}
\hline & Absolutive & Ergative \\
\hline 1SG & $=\mathrm{en}$ & $=\mathrm{ne}$ \\
1PL.EXCL & $=\mathrm{esh}$ & $=\mathrm{che}$ \\
1PL.INCL & $=\mathrm{che}=$ 'el & $=\mathrm{che}=\mathrm{me}$ \\
$2 \mathrm{SG}$ & $=(') \mathrm{et}$ & $=(') \mathrm{ep}$ \\
$2 \mathrm{PL}$ & $=\mathrm{el}$ & $=' \mathrm{em}(\mathrm{e})$ \\
$3 \mathrm{SG}$ & $=\mathrm{et}$ & $=\mathrm{p}(\mathrm{e})$ \\
$3 \mathrm{PL}$ & $=\mathrm{el}$ & $=\mathrm{me}$ \\
\hline
\end{tabular}

We observe syncretism in the $2 \mathrm{pl}$ and $3 \mathrm{pl}$ absolutive. Although the table above indicates distinctions between the other pairs of second and third person forms, the surface realizations of these forms do not make it clear that they are not syncretic at the point of vocabulary insertion. At the very least, there are examples where the third singular absolutive form triggers glottal stop epenthesis, and there are also cases where the third singular ergative form is realized (and glossed) as 'ep, hence identical in form to their analogues in the second person:

a. me=she='et qay hax ami'an pehiwqal pukuyka pekelawika and $=\mathrm{DUB}=3 \mathrm{sg}$.abs not who close $3 \mathrm{sG}$.be $3 \mathrm{sG}$.to.fire 3sG.to.firewood heteyaxapi crouch-yaxa-subir

'There must be nobody there to sit by his fire, by his firewood.'

b. e='ep haxiy qwa'ish pe-kwaani a'chiwi-qa

2SG.PRO=3sg.erg who food 3SG-for make-PRES

'Who are you making that food for?'

This is more of a data problem than an analytic one, however, as they all involve pairs of second- and third-person forms which always agree in number and alignment. The syncretism in the $2 \mathrm{pl}$ and $3 \mathrm{pl}$ absolutive forms are regular, and if we are to treat the remaining second person and third person forms as syncretic as well, the analysis would extend straightforwardly.

Subject marking in the non-past is conditioned by the transitivity of the predicate. Transitive and intransitive predicates are associated with distinct forms of subject marking in the clitic complex.

a. $\mathbf{e m}=\mathbf{e l}=$ pe tukumay peta'a-nim tanim

2PL.PRO $=\mathbf{2 p l . a b s = I R R ~ t o m o r r o w ~ a l l . P L ~ d a n c e ~}$

'Tomorrow every one of you will dance.'

b. tamika='em=pe mi=yawichin $\mathrm{me}=\mathbf{e} \mathbf{m}=$ pe $\mathrm{mi}=$ wichaxin

to.sun $=\mathbf{2 p l . e r g}=\mathrm{IRR} 3 \mathrm{PL} . \mathrm{OBJ}=$ take.in and $=\mathbf{2 p l . e r g}=\mathrm{IRR} 3 \mathrm{PL} . \mathrm{OBJ}=$ throw.in

'You will take them to the east and you will throw them.'
a. na-nxalu've-i-im=el
puy-we
DUP-old.man-NPN-PL $=3$ pl.abs dine-PRPL

'The old men are eating.' 
b. pem-sawi $=$ me kwa-we 3PL-bread $=3$ pl.erg eat-PRPL

'They are eating their bread.'

The same subjects display distinct marking in the (a) and (b) examples. In the (a) examples the predicates are intransitive and in the (b) examples they are transitive.

The observation that subject marking is conditioned by transitivity is consistent with either an ergative-absolutive alignment or a tripartite alignment. In an ergative-absolutive alignment (7a), the marking associated with both the intransitive subject (A) and the direct object $(\mathrm{O})$ is identical to the exclusion of marking associated with the transitive subject $(\mathrm{S}) .^{3}$ In a tripartite system $(7 \mathrm{~b})$, all core arguments $\mathrm{A}, \mathrm{S}$, and $\mathrm{O}$ display unique marking.

(7) Morphosyntactic Alignment Patterns

a.

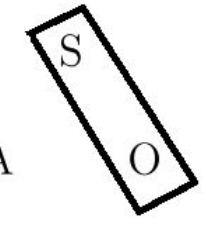

b. S

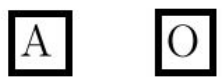

In Cupeño, we observe that the object marking on the verb is not identical in form to the intransitive subject marking: if it were we would expect a morpheme with a / $/$ to appear for $2 \mathrm{sg}$ objects (absolutive), but instead we observe the proclitic $i=$.

(8) $\quad$ ne'=ne i=tuvyung-qa mixanuk e-'ichaaywiqali

1SG.PRO=1SG.ERG 2sg.obj=ask-PRS how $\quad 2 \mathrm{SG}-\mathrm{do}$

'I'm asking you how to do it.'

Thus we can be certain that Cupeño actually exhibits tripartite alignment. The form of subject-marking in non-past tense correlates with the transitivity of the object as indicated by the table in (3). The form of object-marking is identical irrespective of transitivity or tense, but displays distinct forms conditioned by person and number as we will see in (9).

\subsection{Object Proclitic on the Verb}

As we have seen above, a proclitic, distinct in form from that seen on intransitive subjectmarking, appears on transitive verbs which indicates the person and number of the object. The forms of this proclitic are given in the table below.

(9) Object Proclitic Forms (Hill 2005:113)

\begin{tabular}{lll}
\hline & Singular & Plural \\
\hline 1 & $\mathrm{ni}=$ & chimi $=$ \\
2 & $\mathrm{i}=$ & $\mathrm{imi}=$ \\
3 & $\mathrm{pi}=$ & $\mathrm{mi}=$ \\
\hline
\end{tabular}
${ }^{3}$ In a nominative-accusative alignment, the transitive and intransitive subjects pattern together to the ex-
clusion of the direct object $(\mathrm{A}=\mathrm{S} \neq \mathrm{O})$. 
As with the ergative subject markers in the non-past, object proclitics have an $/ \mathrm{m} /$ in their plural forms. This may be the overt realization of plural marking.

As the examples below show, the object proclitics are not sensitive to tense in the way that the subject clitics are.
a. qay mi-pa $\mathbf{m i}=$ tewiqtam
not INDEF-time $\mathbf{3 p l . o b j = s e e . P L ~}$
'[You (pl.)] will never see them again.'
b. $\mathrm{mu}=\mathrm{ku}$ 'ut aya pe-na'aqwanmi $\mathbf{m i}=$ kwaw-pe-n
and $=$ REP then 3sG-child.PL $\mathbf{3 p l . o b j = c a l l - 3 S G - I N ~}$

'And then it is said he called his children.'

Hill observes that while most object clitics are obligatory, third person singular clitics display more variability in their realization. She contends that the presence of third, singular clitcs is used for discourse-configurational purposes. Further investigation is necessary to determine if this functional analysis is correct. Alternatively, it may be that the presence or absence of object-marking is an instance of Differential Object Marking (DOM) conditioned by definiteness/specificity.

The proclitic reflects PN agreement for direct (10b), indirect (11a), and benefactive (11b) objects. We see in (11a) that in cases with both direct and indirect objects, the direct object is reflected on the proclitic.
a. qay='ep hish e-'achi chimi='uni-qa
not $=2$ SG.ERG what 2SG-pet 1pl.obj-show-IN-PRS

'You did not show us your pet.'

b. $\quad$ em-em $=$ qwe $=$ me $\quad$ chimi $=$ mixáan me chimi $=$ meqan-max

2PL.PRO-PL=can=2pl.erg $\mathbf{1} \mathbf{p l . o b j}=\mathrm{do} \quad$ and $\mathbf{1} \mathbf{p l . o b j = k i l l - B E N E F A C T I V E}$

hunwet pe' aya chimi=tul-qa

bear DET now $\mathbf{1} \mathbf{p l . o b j = f i n i s h - P R E S}$

'You (pl.) must do something for us, and kill for our sake the bear who is now finishing us off.'

(H113)

For the remainder of this paper, we will only be concerned with direct object-marking.

\subsection{Past Constructions: Subject Affixes on the Verb}

In past tense contexts, subject marking fails to appear in the clitic complex. Instead, subjects are encoded as an affix on the verb.

Subject Affix Forms in the Past Tense (Hill 2005:109)

\begin{tabular}{rll}
\hline & Singular & Plural \\
\hline 1st & ne & chem \\
2nd & e & em \\
3rd & pe & pem \\
\hline
\end{tabular}


Verbs may be subdivided into three classes: zero, -in, and -yax, assigned based on what affix, if any, appears on the verbal root. Note that the classes are properties of "derived" verbs and not of roots - a given root may appear in two separate classes. The -in and -yax morphemes have some regularity in their semantics, which we will discuss below.

In terms of subject marking, the markers appear to the left of the verbal root for zeroclass verbs and to its right (but to the left of the -in and -yax suffixes) in -in and -yax class verbs. Hence, Hill describes the verbal template of Cupeño for past tense verbs to be the following, where PNO denotes the PN object proclitic of the previous subsection, $\mathrm{PNS}_{\varnothing}$ the PN subject marking for zero class verbs, and $\mathrm{PNS}_{i / y}$ the PN subject marking for -in/-yax class verbs.

$$
\mathrm{PNO}=\mathrm{PNS}_{\varnothing}-\text { Root }-\mathrm{PNS}_{i / y} \text { - Theme - Derivational (-in/-yax) - Tense/Aspect }
$$

Illustrative examples using the three verb classes are below.

$$
\begin{aligned}
& \text { a. ne-túl 'I finished.' } \\
& \text { b. chem-tewás 'We lost.' }
\end{aligned}
$$

-in, -yax Class: Subject PN Suffixed
a. het-pe-yax
crouch-3sg.nom-yax
'He crouched.'
b. haw-che'-men
sing-1PL-in.PL
'We were singing.'

The variable position of subject agreement morphology in (14) and (15) appears prima facie to be problematic for the Mirror Principle (Baker 1985). We expect the features of the same node to be realized in the same position. If subject agreement resides in $\mathrm{T}^{0}$, as is commonly assumed since at least Chomsky $(2000,2001)$ we would expect it to appear outside all other verbal morphology.

Barragan suggests that the solution to this confound is syntax-internal. Specfically, he posits that - in and $-y a x$ are overt realizations of $\mathrm{v}^{0}$. Evidence for this position comes from Harley (2007), who shows that -in and -yax alternate with one another in a standard causative/inchoative pairing:
a. chashr-in 'to polish something' chashr-yax 'something shines'
b. chaqw-in 'to flatten'
chaqe-yax 'to be oblique'
c. chene-in 'to roll something' chene-yax 'something rolls'
d. chilyi-in 'jingle something'
chilyi-yax 'something jingles'
e. hiwe-in 'to heat to lukewarm'
hiwe-yax 'something is lukewarm'
f. puve-in 'to make round'
puve-yax 'something is spherical' 
Given this alternation, Harley concludes - in is $\mathrm{v}_{\mathrm{CAUSE}}$ and - yax is $\mathrm{v}_{\mathrm{BECOME}}$.

Analyzing - in and - yax as overt instantiations of $\mathrm{v}^{0}$ allows Barragan to explain the varying position of subject agreement morphology. Specifically, he suggests that the verb undergoes Head Movement to $\operatorname{AgrS}^{0}$ ( $\mathrm{T}^{0}$ in the current framework). Such movement is posited to occur because of an [affix] feature on $\mathrm{AgrS}^{0}$. However, the part of the verb that undergoes movement varies. In $\varnothing$-class verbs, $\mathrm{v}^{0}$ lacks a verbal element, hence the verbal root is the only verbal element and must move from $\mathrm{V}^{0}$ to $\operatorname{AgrS}^{0} / \mathrm{T}^{0}$. When $\mathrm{v}^{0}$ is filled in - $i n$ and -yax class verbs, these elements, which are structurally closer than the verbal root, moves to AgrS0 $/ \mathrm{T}^{0}$, and the movement indicated by the dashed arrow in (17) does not occur.

Head Movement from $\mathrm{V}^{0}$ and $\mathrm{v}^{0}$ (Ex. 24-25 from Barragan (2003)):

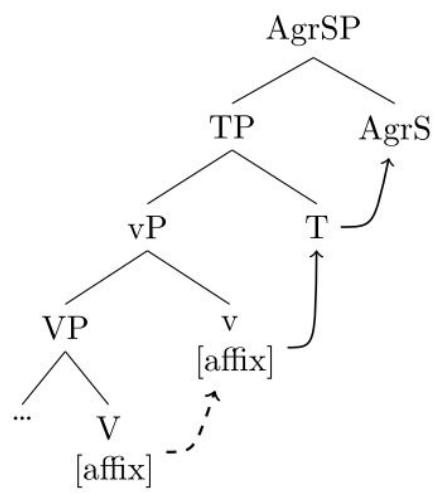

On the assumption that Head Movement occurs within the narrow syntax (e.g., Travis (1984), Matushansky (2006), contra Chomsky (2000), Harley (2004)), post-syntactic morphological operations must still apply. In $\varnothing$-class verbs, subject agreement appears to the left of the verbal root, while in -in and -yax class verbs, subject agreement appears to the left of these affixes. This is unexpected if subject agreement is generated on the head of AgrSP or $\mathrm{TP}$ and these projections are head-final. Under these assumptions, we would expect subject agreement to appear to the right of the verbal element which raises to $\operatorname{AgrS}^{0} / \mathrm{T}^{0}$. Barragan overcomes this complication by employing Local Dislocation (Embick \& Noyer 2001) prior to vocabulary insertion. Local Dislocation permits subject agreement morphology to relinearize to the left of only those elements which have undergone Head Movement to $\operatorname{AgrS}^{0} / \mathrm{T}^{0}$. As a result of this relinearization process, subject agreement morphology will be prefixal. It should be noted that the specific analysis of the positioning of subject agreeement is not crucial the current proposal. We are chiefly concerned with the form this subject-marking takes, not with its location. We turn to this concern now.

The subject affix in past tense, aside from positioning, differs from its non-past counterpart in its alignment property. There is a single series of affixes which marks subjects of both transitive and intransitive verbs. Hence they are not aligned as ergative-absolutive, but rather exhibit nominative behavior.

a. me aya ataxam mi=kwaw-pe'-men-wen and then person.PL 3PL.ACC=call-3pl.nom-IN.PL-PST.IMP.PL

'And then they called the people.' 
b. pe-shúun-i pi=kulu-lu-pe-n-ngiy

3SG-heart-OBJ 3SG.OBJ=drag-RED-3sg.nom-IN-motion.going.away

'He went away dragging his heart.'

In summary, Cupeño PN morphology (in general) takes the following form.

(19) a. Subject PN morphology is realized distinctly in past and non-past tenses: in the former as verbal morphology, in the latter as a Wackernagel clitic.

b. Past tense subject PN morphology displays a nominative alignment, taking the same form regardless of transitivity.

c. Non-past tense subject PN morphology displays an ergative alignment. The form of the marker correlates with transitivity.

d. Object PN morphology, when present, is realized as a proclitic on the verb and is sensitive to neither tense nor transitivity.

The observation that subject PN morphology shifts from ergative to nominative as tense shifts from non-past to past has led some to conclude that Cupeño is a split-ergative language. In the next section, we offer an alternative proposal to this apparent alternation, arguing that Cupeño is better analyzed a case-agreement mismatch language where the case marking is uniformly tri-partite while verbal agreement is uniformly nominative. In this regard the language is like Nez Perce (Deal 2013) and Nepali (Bobaljik 2008). Unlike these languages, the overt realization of both case and agreement is conditioned by tense yielding the illusion of TAM-based split ergativity. In Section 4, we provide additional argumentation against a split-ergativity analysis.

\section{Cupeño Displays a Regular Syntax}

In this section, we provide an analysis of Cupeño's regular syntactic processes. Again, we will contend that the language is uniformly tripartite in case and nominative in agreement. The apparent split-ergativity is epiphenomenal.

\subsection{Case in Cupeño Clitics}

As we have seen above, Cupeño shows a tripartite case alignment. Subjects of both unergative and unaccusative predicates license absolutive clitics. In transitive predicates, subject clitics are marked with ergative case. Furthermore, objects of transitive clauses do not license clitics with case-marking identical to intransitive subjects which would be expected in an ergative-absolutive alignment. Rather, object clitics bear a third, distinct case-marking (10) which we will label accusative.

We suggest that a tripartite system can be straightforwardly captured under a configurational system of case-assignment, whereby the case assigned to a nominal element, and thus reflected on the clitic generated with it, can be sensitive to the presence and/or absence of other local nominals. At this point, we find no strong motivating factors to push 
us to adopt either a configurational or more commonly held Agree-based model for caseassignment (Chomsky 2000, 2001) in Cupeño. ${ }^{4}$ Thus, the use of a configurational based model is nothing more than a stylistic choice. However, there may yet be some stronger motivation for favoring one over the other which we have not yet discovered.

\subsubsection{Configurational Case Assignment}

The configurational model assigns case to a noun-phrase based on the interplay of two factors: the identity of the head that (c-)selects it and the position of the noun-phrase relative to others in the clause (Yip et al. (1987); Marantz (1991); see also Bittner \& Hale (1996)). Procedurally, we follow Marantz's (1991) disjunctive case hierarchy:

(20) Disjunctive Case Hierarchy

lexical/oblique case $>>$ dependent case $>>$ unmarked case

Let us now consider how (20) works. First, all noun-phrases that are selected by lexical items which idiosyncratically specify a particular case-marking for their arguments (prepositions, verbs that govern so-called quirky case, etc.) are assigned the idiosyncratic case in question.

Next, all those noun-phrases that did not receive case in the previous step are evaluated. For every pair of as-of-yet caseless noun-phrases within a local domain that stand in an asymmetric c-command relation, one will be assigned dependent case (in an ergative language/construction, the higher of the two will get this case-marking, and we can informally call it "ergative"; otherwise, the lower of the two will get this case-marking, and we can informally call it "accusative"). This is schematized in (21).

Case Competition $\rightarrow$ Dependent Case

a.

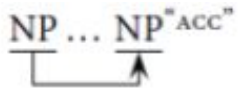

b.

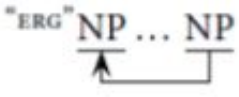

(nominative-accusative)

(ergative-absolutive)

This stage of the algorithm is sometimes referred to as case-competition - the idea being that dependent case is assigned to a noun-phrase by virtue of a competing as-of-yet caseless noun-phrase. Note that case-competition cannot be a reciprocal relation, since that would falsely predict that both of the competing arguments could be assigned dependent case; instead, it must be unidirectional, with the direction parameterized as in (21).

In the final step, every noun-phrase that has been assigned lexical/oblique or dependent case in the previous steps will be assigned unmarked case, which we can informally call nominative or absolutive (or in the nominal domain, genitive). The term unmarked case is not to be confused with default case or citation form: in English, for example, fragment

\footnotetext{
${ }^{4} \mathrm{~A}$ problem faced by the Agree-model is that tripartite systems are sensitive to the presence/absence of another nominal as the case of a transitive subject is distinct from an intransitive subject. This is immediately reminiscent of a Dependent Case theory in which nominals act as case-competitors with one another. Nevertheless, a number of analyses of ergative case-marking have been advanced within the Agree model. See for instance Woolford (1997) and Legate (2008) a.o.
} 
answers and other free-standing forms bear accusative, the dependent case (Who came to the party? Him $/{ }^{*} \mathrm{He}$ ). Instead, the term unmarked case refers to case-marking whose appearance is neither idiosyncratically conditioned nor dependent on the appearance of other nounphrases in the clause. What its name is meant to suggest is a cross-linguistic tendency to be phonologically empty or phonologically lighter than dependent case and lexical/oblique case.

\subsubsection{Capturing a Tripartite System}

As we can see from the description above, the configurational case-assignment algorithm in its original formulation is not set up to handle a tripartite system, although it captures quite straightforwardly the distribution of both ergative and absolutive case. Nevertheless, we can directly extend the possible parameterizations of dependent case to capture a tripartite system.

As we saw above, the only difference between an ergative system (21a) and an accusative system (21b) is which of two nominals in an asymmetric c-command relation receives dependent case. In the former, the c-commanding nominal received dependent case, while in the latter it was the c-commanded nominal which received dependent case. We suggest that in a tripartite system both nominals in an asymmetric c-command relationship (within a caseassignment domain) can receive dependent case. The c-commanding nominal will receive dependent ergative case and the c-commanded nominal will receive dependent accusative case. Only when a single nominal exists in a case-assignment domain, regardless of its baseposition in Spec-vP (unergative) or Compl-V (unaccusative), will it receive unmarked case which we can informally call absolutive. We can schematize this proposal for a tripartite system as in (22).

Tripartite Case Assignment

a. NP"ERG" ... NP"ACC"

(transitive clauses)

b. ... $\mathrm{NP}^{\text {"ABS" }} \ldots$

(intransitive clauses)

The realization of two distinct forms of dependent case within a single language is not a novel proposal. Baker \& Vinokurova (2012) suggest that in Sakha dative case is dependent case assigned to an indirect object which c-commands a direct object within the VP, and accusative is assigned to direct objects which undergo object shift out of the VP to be ccommanded by the subject within the CP-domain. Furthermore, Deal (2013) independently notes that simultaneous assignment of both dependent cases can capture the behavior of tripartite case in Nez Perce.

Having outlined the Marantzian theory of case assignment as specified for a tripartite language in general, we can now address its implementation in Cupeño. As we have seen, Cupeño does not realize case-marking on subject DPs themselves. Rather, it is the argument clitics which host case specification. We suggest that clitics can be valued for case in the same manner as nominals if clitics are generated with the same constituent as their nominal host. An ingredient of the analysis is that of the big-DP shell as an added syntactic layer within which clitics are hosted (Torrego 1992; Uriagereka 1995). Crucially for the aspect of case assignment, the clitics are generated within the KP shell of the doubled argument.

We claim that the structure is as follows. 


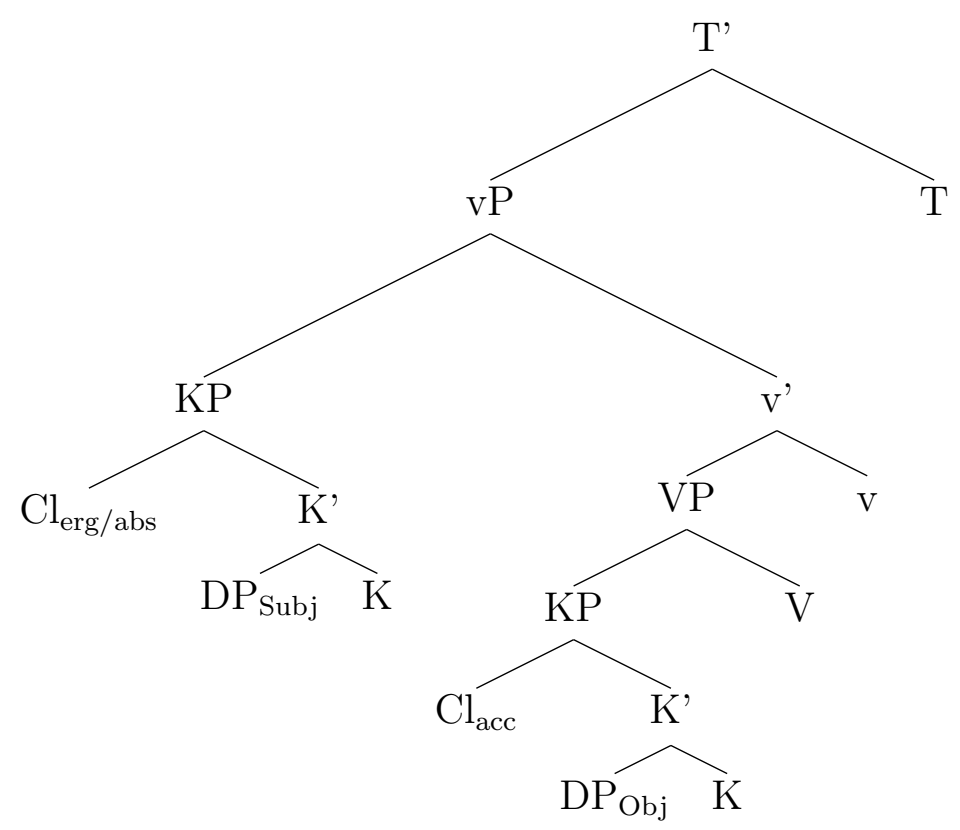

If case competition takes places within the narrow syntax as soon as possible (Baker \& Vinokurova 2010; Preminger 2011b), then the entire KP will be valued for case. We posit that the morphological realization of case on subject nominals is on the clitics and that the associated DPs do not have distinct forms which correlate with case marking. ${ }^{5}$ If KPs are case competitors in Cupeño, then the subject clitic will be realized as dependent ergative only when there is a competing object KP which is (optionally) realized as dependent accusative. In intransitive predicates, there is only one $\mathrm{KP}$ in the derivation, which will be realized as unmarked absolutive

We contend that case-assignment as described here occurs consistently across tenses: regardless of tense, transitive subject KPs are ergative, intransitive subject KPs are absolutive, and object KPs are accusative. Below, we suggest that the realization of this case-marking is limited to non-past tense because subject clitic hosting is sensitive to tense. First, we introduce our proposal for verbal agreement, which is also highly regular.

\subsection{Agreement in Cupeño}

As we have seen, the realization of subject agreement on the verb has two major constraints: (i) it only appears on past tense verbs, and (2) it appears in one of two different positions depending on verb class. We have adopted Barragan's analysis of the latter point, positing that a combination of head-movement and Local Dislocation can account for the variable position of the subject agreement morphology within the verbal stem. In this section, we will lay the ground work for addressing the former point. Again, we will contend that subject agreement, though its overt realization correlates with tense, is not interrupted in non-past. Rather, agreement takes place, but is simply left covert.

It is commonly accepted that subject agreement morphology is the overt realization of $\varphi$ agreement between $\mathrm{T}^{0}$ and the subject (Chomsky 2000, 2001). Under this view, $\mathrm{T}^{0}$ bearing

\footnotetext{
${ }^{5}$ Object DPs do bear case, as we see in example (46). This is predicted by our analysis, as any element generated in the $\mathrm{KP}$ - both the clitic and the host DP - can bear case.
} 
unvalued $\varphi$-features probes the derivation, finding the subject which bears valued $\varphi$-features. After locating an appropriate host, the $\varphi$-features on $\mathrm{T}^{0}$ are valued by those on the subject DP. Interestingly, at the same time, $\mathrm{T}^{0}$ 's case-feature values the unvalued case-feature of the subject. As mentioned above, this model is disadvantageous when considering languages like Cupeño which display non-uniform subject marking. If $\mathrm{T}^{0}$ always enters an Agree relation with the subject, it is not (immediately) clear why the subject should bear variable case-marking. To avoid this problem entirely, we instead opted to utilize the Dependent Case model of case assignment. Having done so, one might wonder how $\varphi$-agreement is captured in this model: the most straightforward way to capture agreement is to make it sensitive to case (see Bobaljik (2008) and Preminger (2011a) for two related attempts). In many languages with non-nominative (or absolutive subjects) these elements do not control $\varphi$-agreement (see Bobaljik (2008) for more details). As such, he proposes that languages paramaterize which case-marked nominals are accessible for agreement. In a language in which only nominative/absolutive arguments control $\varphi$-agreement, it is only those nominals which bear unmarked case that serve as a viable target for $\varphi$-feature valuation. In a language like Cupeño however, we have seen that affixal subject agreement marking is consistent regardless of the transitivity of the verb (18). Under the view espoused in the previous subsection, the transitive subject is underlyingly ergative while the intransitive subject is underlyingly absolutive. As such, both unmarked and dependent case appear capable of controlling agreement and a different parameterization is needed.

Crucially, we contend that $\mathrm{T}^{0}$ always targets the structurally highest nominal, where "higher" is defined as a c-commanding relation. As such, the subject will control agreement regardless of case. This process is also insensitive to tense. Hence $\varphi$-agreement occurs in both past and non-past contexts. It is only the overt realization of this process that is limited to past tense. ${ }^{6}$

\subsection{The Split-ergativity Illusion}

So far we have suggested that case and agreement in Cupeño are regular. That is to say, the syntactic processes which control them within the narrow syntax always occur. Caseassignment occurs as outlined in section 3.1 and agreement occurs as outlined in 3.2. These processes yield a uniform tripartite case alignment and nominative agreement alignment. We

\footnotetext{
${ }^{6}$ Barragan also suggests that the feature [Past] conditions the appearance of subject agreement. Working within the AgrP framework of Chomsky (1995), Barragan assumes that subject agreement heads its own projection above TP. For him this is problematic, because he contends that AgrSP hosts $\varphi$-agreement while TP hosts tense specification. Such a structure is problematic for featurally conditioned allomorphy because the direction of conditioning is unexpected. Under such analyses (e.g., Bobaljik (2000)), it is commonly thought that features are erased as they are filled in with phonological information. If we take morphological operations to precede bottom-up, then the relevant feature ([Past] on $\mathrm{T}^{0}$ ) will be erased before it can trigger allomorphy on AgrS0 above it. In this view, subject agreement should never show any sensitivity to feature-based allomorphy, due to its high structural position.

Barragan suggests a solution may be found in fusion. Specifically, if the adjacent nodes $\mathrm{T}^{0}$ and $\operatorname{AgrS}^{0}$ fuse before vocabulary insertion, a complex head will be formed that includes featural information of both nodes. Vocabulary insertion crucially proceeds after this operation, filling in the complex head for all relevant features. Thus when the complex head contains PN features and a [Past] feature it will be filled with overt material. When the complex node lacks the [Past] feature it will be realized as null.
} 
have offered specifics for implementing these alignments above, but note that they may be achieved by other means as well. In total, the PN morphology of Cupeño can be captured as below:

(24) Syntactic Architecture in Cupeño: Dependent Case Assignment and $\varphi$-agreement

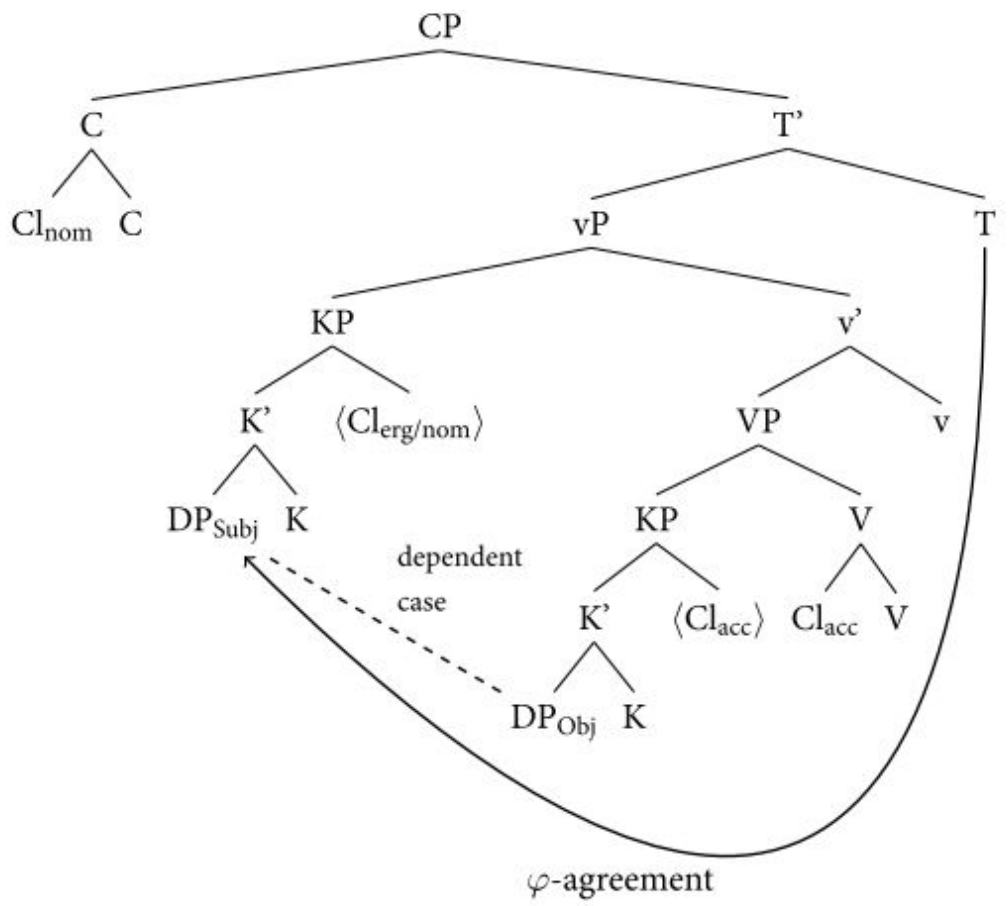

When the subject KP enters the derivation case competition immediately occurs. If the predicate is transitive, as diagrammed above, and an object KP is present (either overtly or not), the subject will receive dependent ergative case and the object will receive dependent accusative. If only one argument is present in the clause, it will receive unmarked absolutive case. When $\mathrm{T}^{0}$ enters the derivation, it will probe its c-command domain for an accessible nominal with valued phi-features. $\mathrm{T}^{0}$ will always target the subject $\mathrm{KP}$ as it is the closest accessible goal, yielding uniform nominative agreement. The exact position within the verbal stem is conditioned by the presence or absence of $\mathrm{v}^{0}$ elements.

What remains to be captured is how the apparent split-ergativity arises. What limits the overt realization of case to non-past tense clauses and $\varphi$-agreement to past tense clauses? We contend that both clitic hosting and subject agreement morphology are sensitive to tense. Clitics cannot be hosted in past tense, thus they disappear. Similarly, subject agreement is realized as null in non-past tense. These two coincidental operations yield apparent splitergativity. In this subsection, we provide motivation for these claims.

\subsubsection{Clitics are Sensitive to Tense}

We contend that ergative-absolutive subject clitics are only realized in non-past tense, becuase clitic hosting is sensitive to tense. We have suggested, above, that clitics in Cupeno are generated along with their host DPs within a KP. We assume that the generation of the 
KP occurs in all tenses. Nevertheless, while clitics are uniformly generated, they may not always find a viable host. When no host is available, the clitic is not pronounced. Arregi \& Nevins (2012), following van Craenenbrock and von Koppen (2008), take a similar approach to clitic hosting in Basque, noting that clitics are sensitive to featural specification. Namely, clitics in Basque are not realized in non-finite clauses:
a. (su-k) (neu) ikus-i $\mathbf{n}=\mathbf{a}=\mathbf{s u}$
(2SG-ERG) (me.ABS) see-PRF 1sg.abs=1sg.pres=2sg.erg

'You have seen me.'

[Arregi \& Nevins 2012]

b. [su-k neu ikus-ti] nai d-au

2sg.ERG me.ABS see=NF want L-3SG.PRES

'He wants you to see me.'

Note that in (25b), no clitic complex is realized in the embedded, non-finite clause. Such observations have their origin in Kayne (1975) and subsequent work on Romance. What is distinct about Cupeño is that the relevant featural specification is not finiteness, but tense. One might wonder why $\mathrm{C}^{0}$ should bear information regarding tense, thought to be hosted in $\mathrm{T}^{0}$. There are a number of technical implementations which could ensure that $\mathrm{C}^{0}$ is sensitive to tense. We might imagine that $\mathrm{C}^{0}$ enters an Agree relationship with $\mathrm{T}^{0}$ (e.g., Pesetsky \& Torrego (2001)). Alternatively, $\mathrm{C}^{0}$ and $\mathrm{T}^{0}$ may share identical features as suggested by Ouali (2008). Additionally, it can be shown empirically that $\mathrm{C}^{0}$ is sensitive to tense. It has been observed in Irish that the form of the complementizer is sensitive to the tense of the embedded clause.

a. an fear a labhrann tu leis

the man crel.npst speak.PRS you with.him

'The man that you speak to'

[Chung \& McCloskey 1987]

b. an fear ar labhair tu leis

the man crel.pst speak.PST you with.him

'The man that you spoke to'

For these reasons, we take $\mathrm{C}$ to be the host of the subject clitic. Diverging from Basque Arregi \& Nevins (2012:57), both ergative and absolutive clitics are hosted by C. The proposed clitic hosts in Cupeño are summarized below.

Clitic Hosts in Cupeño

a. Non-[Past] C hosts ergative and absolutive clitics.

b. V hosts accusative clitics.

Crucially, as $\mathrm{V}^{0}$ is never specified for tense, we expect object clitics to be hosted regardless of tense. This expectation is borne out, as seen in (10).

\subsubsection{Agreement is Sensitive to Tense}

Like clitic hosting, we contend that agreement may also be sensitive to tense. Specfically, though the process of Agree takes place between $\mathrm{T}^{0}$ and the subjet regardless of tense, only 
in past tense is the result of this operation realized overtly. It is well-known that agreement may be sensitive to tense. English, for instance, displays (impoverished) $\varphi$-agreement in present tense, but uniform agreement in past tense.

(28) English Verbal Agreement and Tense

a. Non-past Tense: 1SG, 1PL, 2SG, 2PL, 3PL: walk; 3SG: walks

b. Past Tense: walked

It is conceivable that Cupeño displays a similar pattern. Namely, in past tense, subject agreement is articulated based on the $\varphi$-features (and case) of the subject while in present tense, agreement is uniformly null.

If these two plausible conditions on the realization of clitics and agreement are simultaneously operative, the illusion of split-ergativity is achieved. In non-past tense, the ergativeabsolutive subject clitic will be hosted on $\mathrm{C}^{0}$ [-past], while subject agreement will be realized as null. In past tense, clitics will not be hosted, and nominative subject greement will be spelled out overtly. In the next section, we entertain alternative analyses that have been suggested for TAM-based split ergativity, noting that these alternatives seem ill-suited for the Cupeño data.

\section{Against a Structural Split-ergative Analysis}

As discussed, the core empirical fact of Cupeño is the following morphosyntactic "split":

a. Non-past tense subjects display ergative-absolutive alignment.

b. Past tense subjects display nominative-accusative alignment.

In the previous section, we accounted for this phenomenon by incorporating existing theories of Case and agreement and arguing that Cupeño is a tripartite language. One immediate challenge to our proposal is that it relies on a morphological coincidence, namely that the two independent subject-markers (as clitic and as affix) are both sensitive to tense, and the realization of one of them is null exactly when the other is not. A counter-proposal may attempt to re-establish the role of the syntax in contributing to the split in Cupeño, analogous to analyses of aspect-based split-ergative languages.

In this section, we outline conceptual and empirical issues that arise with a syntactic treatment of the phenomenon as tense-based split-ergativity, and argue that the proposal would be untenable without appeal to the morphological component.

\subsection{Empirical Problems}

The Cupeño data are at odds with cross-linguistic tendencies of split-ergative systems. Consider the following generalization from Dixon's (1994) seminal work on ergativity:

(30) Ergative Split Generalization (Dixon 1994)

If a split is conditioned by tense or aspect, the ergative marking is either found in the past tense or the imperfective aspect. 
If Cupeño was a split-ergative system, it would be a counter-example to this generalization as ergative alignment (i.e., transitivity-sensitive subject-marking) is exhibited in the non-past tense and not in the past tense. Similarly, in line with Dixon's generalization, splits correlate with the non-perfective aspect in widely unrelated languages.
a. emakume-a-k ogi-ak ja-n d-it-u woman-DET-erg bread-DET.PL eat-PERF 3.ABS-PL-have.3.ERG

'The woman haas eaten the breads.'

[Basque, Laka 2006]

b. emakume-a- $\varnothing$ ogi-ak ja-te-n ari da woman-DET-abs bread-DET.PL eat-NML-LOC PROG 3.ABS.is

'The woman is eating (the) bread.'
a. Raam-ne roTii khaayhii thii
Raam-erg bread.FEM eat.PERF.FEM was.FEM
'Ram had eaten bread.'
b. Raam- $\varnothing$ roTii khaataa thaa
Ram-nom bread.FEM eat.IMPF.MASC was.MASC
'Ram (habitually) ate bread.'

[Hindi, Mahajan 1990]

Moreover, recent research has suggested that all TAM split-ergative systems might be reduced to aspect splits (Salanova 2007; Coon 2010). As we see in the examples below, Cupeño does not show such alternations between perfect and imperfect constructions.

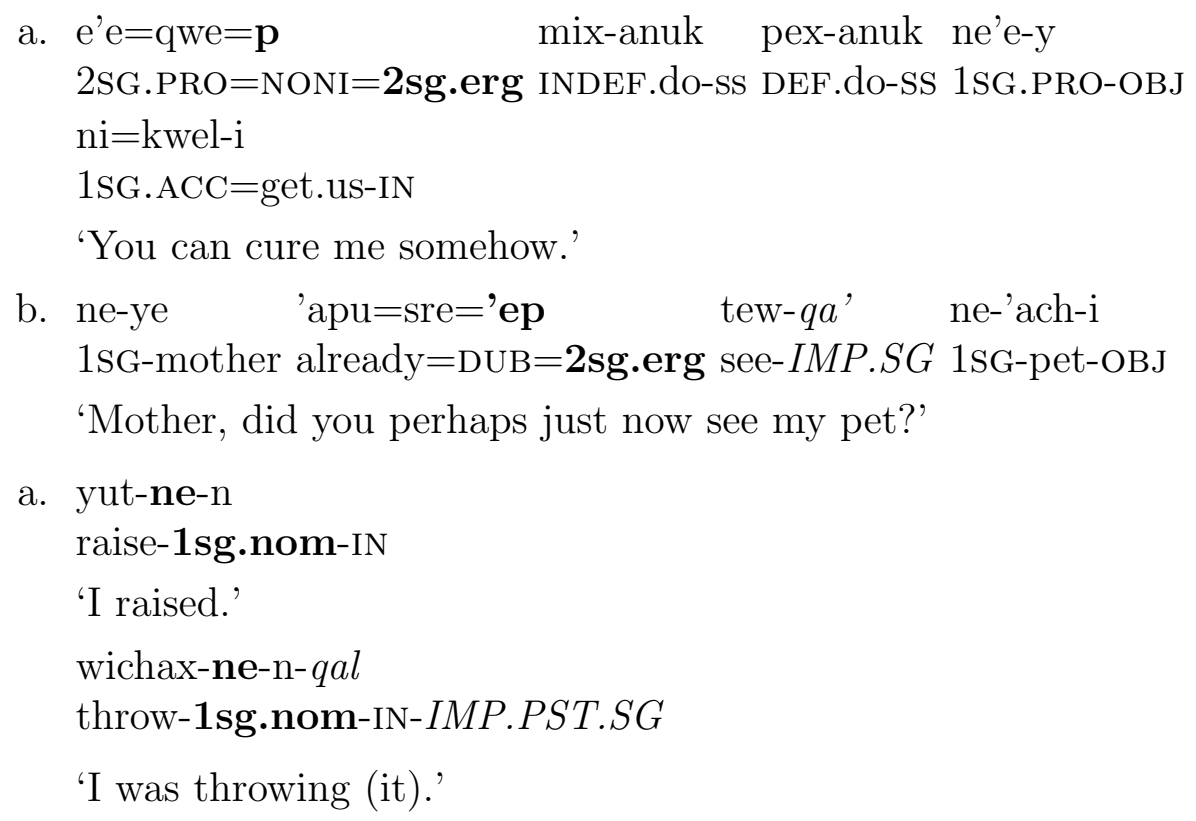

In (33)-(34), the presence or absence of non-perfective morphology has no consequence for subject-marking. In non-past tense, the subject-marking is uniformly ergative-absolutive. In past tense, it is uniformly nominative. Of course, generalizations are made to be broken we must entertain the possibility that Cupeño poses a true counter-example to these claims. 


\subsection{Conceptual Problems}

Coon (2010) has advanced the following claim that aspect-based split-ergativity is conditioned by biclausality: a transitive predicate can be decomposed into two intransitive predicates.

(35) Split Proposal (Coon 2010)

In nonperfective aspects which show 'split ergativity,' ergative Case is absent in transitive clauses because the subject is assigned Case not by the lexical verb, but by an intransitive aspectual verb.

As empirical evidence, Coon discusses examples from Chol (Mayan), where clauses embedded under aspect (36) look identical to those embedded under canonical embedding predicates (37).

(36) Embedding Under Progressive

a. choñkol [k-wuts' jiñi pisil]

PROG 1.ABS-wash DET clothes

'I am washing the clothes.'

b. choñkol [k-majl-el]

PROG 1.ABS-gO-NML

'I am going.'

c. choñkol [k-mejk'-el]

PROG 1.ABS-hug-PASV-NML

'I am being hugged.'

(37) Embedding Under 'want'

a. k-om [k-wuts' jiñi pisil]

1.ABS-want 1.ABS-wash DET clothes

'I want to wash the clothes.'

b. k-om [k-majl-el]

1.ABS-want 1.ABS-go-NML

'I want to go.'

c. k-om [k-mejk'el]

1.ABS-want 1.ABS-hug-PASV-NML

'I want to be hugged.'

In other words, transitive predicates are decomposed into two intransitive predicates, with non-perfective aspect adding structure. The contrast is represented schematically in (38). In the ergative alignment, no additional structure is present and as such syntactic operations, like Dependent Case assignment, are not interrupted. In the split-alignment, the presence of additional structure (indicated by the boundary line), triggered by non-perfect morphology in TAM-based splits, and Participant Phrases in person-based splits serves to interrupt such 
processes making dependent ergative case realization impossible, because the relevant case competitors no longer occupy the same local domain (Coon \& Preminger 2012). ${ }^{7}$

(38) Ergative vs. Split Alignment (Coon \& Preminger 2012)

(10) ERgative ALIGNMENT

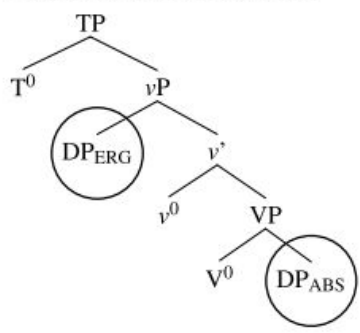

(11) "SPLIT" ALIGNMENT

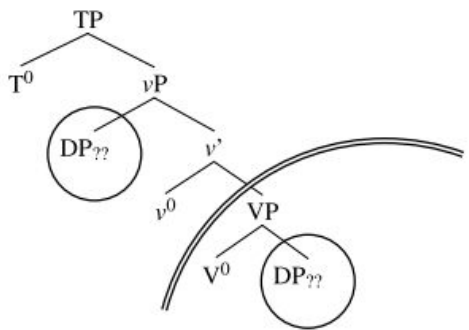

Hence, if split-ergativity implies biclausality, we might expect to find evidence of subordinated biclausality in the Cupeño past tense. However, such clauses display none of the characteristics that are associated with subordination. To see this, we note three ways in which Cupeño expresses subordination. First, adverbial subordination is signaled by switch reference marking.
a. $m u=k u ' u t ~ p i=' a m-i-n u k$, $\mathrm{pi}=\mathrm{pe}-\mathrm{meq}$ and $=$ REP $3 \mathrm{SO}=$ knock.down-IN-ss $3 \mathrm{SO}=3 \mathrm{~s}-\mathrm{kill}$

'And it is said that having knocked him down, he killed him.'

b. pe-ting-qali=ku'ut pe-nene-wen 3s-be.hot-ds=REP 3s-go.around-PIST

'He used to walk around when it was hot.'

Secondly, sentential complements and relative clauses bear mood marking on the predicate.

a. $m e=q w e=m e$ aya mixa-nuk hiwchu-wene ne-'ash

and $=$ NONI $=3$ PL.ERG now be-SS know-CUSTPL 1s-pet

pe-hiw-qali-ve

3s-be.there-PISi-subr

'So how do they know my pet is alive.'

b. mu=ku'ut pem-yax pe-meqa-pi

AND $=$ REP 3PL-say 3s-kill-subi

'And it is said they said for him to kill it.'

Finally, deverbal morphology is realized through suffixes such as -sh which are used for non-possessed nouns.
a. ne-nee' $\mathrm{e}=\mathrm{m}$ tewahi-sh
1s-basket-MIR lose-npn
'My basket is lost.'

\footnotetext{
${ }^{7}$ Coon \& Preminger (2012) suggest that additional structure could similarly interrupt Agree-based case assignment.
} 
b. "ixa-nuk='ep atax-m-i yeve-ni-sh," pe-yax=u'ut
do-SS=R person-PL-O bury-IN-npn 3 S-say=REP

"'In this way people are buried," he said, it is said.'

The three strategies employed above are not attested to represent the past tense, and the biclausality associated with split-ergativity is not maintained in Cupeño.

a. tekwaye $=$ she kwini-ly-i pem-chi

long.ago $=$ DUB acorn-NPN-O 3PL-gather

'Long ago they must have gathered acorns.'

b. tuku='ep ne-a'alxi, qay ne-tul

yesterday $=$ R 1SG-recite.history not 1SG-finish

'Yesterday, I told history. I did not finish.'

c. Oceanside-nga'aw='ep ne-nene-wen tuku

Oceanside-at $=\mathrm{R} \quad$ 1s-go.around-PIST yesterday

'I was in Oceanside yesterday.'

One final point to be made is that in general, $\mathrm{T}$ is located above the base position of the subject - see McCloskey (1997) for a review. Thus, if case-assignment occurs as soon as possible (Baker \& Vinokurova (2010)), then case will be determined before $\mathrm{T}^{0}$ enters the derivation. Namely, case competition will take place when the subject enters the derivation in Spec-vP. As such, it would be impossible for $\mathrm{T}^{0}$, which carries tense specification, to interrupt the case assignment process, yielding a syntactic ergativity split.

In summary, Cupeño patterns differently from other languages that have been classified as split-ergative. While it is possible that generalizations over such languages are incorrect, diagnostics for complex structure arising from split-ergativity also fail in Cupeño, and it appears that the analysis which appeals to morphological operation is the most parsimonious.

\section{Further Remarks on the Derivation Under DM}

We conclude our discussion of Cupeño PN morphology by making more explicit the Distributed Morphology operations which we have appealed to thus far.

\subsection{Unification of PN Morphemes}

We reproduce here from $\S 1$ the forms of the affixes and clitics.

(43) Past Subject PN Affixes \& Object Proclitics on the Verb (Hill 2005:109, 113)

\begin{tabular}{|c|c|c|c|c|c|}
\hline & Singular & Plural & & Singular & Plural \\
\hline 1 & $\mathrm{ni}=$ & chimi $=$ & 1 & ne & chem \\
\hline 2 & $\mathrm{i}=$ & $\mathrm{imi}=$ & 2 & e & em \\
\hline 3 & $\mathrm{pi}=$ & $\mathrm{mi}=$ & 3 & pe & pem \\
\hline
\end{tabular}


(44)

\begin{tabular}{|c|c|c|}
\hline & Absolutive & Ergative \\
\hline $1 \mathrm{SG}$ & $=\mathrm{en}$ & $=$ ne \\
\hline 1PL.EXCL & $=\mathrm{esh}$ & $=$ che \\
\hline 1PL.INCL & $=\mathrm{che}=$ 'el & $=\mathrm{che}=\mathrm{me}$ \\
\hline $2 \mathrm{SG}$ & $=(')$ et & $=(') \mathrm{ep}$ \\
\hline $2 \mathrm{PL}$ & $=\mathrm{el}$ & $=' \operatorname{em}(\mathrm{e})$ \\
\hline $3 \mathrm{SG}$ & $=\mathrm{et}$ & $=\mathrm{p}(\mathrm{e})$ \\
\hline 3PL & $=\mathrm{el}$ & $=\mathrm{me}$ \\
\hline
\end{tabular}

It is immediately obvious that the absolutive series of subject clitics is the "odd man out" among PN morphology. This is made even more striking when comparing the morphemes to pronouns:

\begin{tabular}{lll}
\multicolumn{2}{l}{ Pronouns } \\
\hline & Singular & Plural \\
\hline 1 & ne' & che-m \\
2 & e' $^{\prime}$ & e-m \\
3 & pe' & pe-m \\
\hline
\end{tabular}

Moreover, the difference between the object proclitic and the subject affix can be accounted for in part by noting that $-i$ appears on full object nominals to denote its status as an object:

$$
\begin{aligned}
& \mathrm{mu}=\mathrm{ku} \text { 'ut pe-nenmin axwech-i kawisich-i } \\
& \text { and=REP 3SG.OBJ-chase DEM-obj fox-obj }
\end{aligned}
$$

'And it is said he chased that fox.'

This asymmetry between the absolutive series and the rest of the PN markers is not surprising, given that Cupeño is unique among the Uto-Aztecan languages for exhibiting ergative-absolutive alignment. Thus, we take the absolutive series to be the innovative form and, aside from the syncretism operation of the following subsection, will treat its vocabulary items as distinct from the others. ${ }^{8}$

\subsection{Second and Third Person Syncretism}

There is syncretism in the non-past subject clitics. ${ }^{9}$ This is accounted for via an Impoverishment rule that removes the distinction between second and third person forms in the 2nd and 3rd person. We take, as discussed above, these subject clitics to be hosted by C.

2nd/3rd Person Number Impoverishment

${ }^{8}$ This isn't to say that the absolutive series lacks regularity or are completely detached from the other PN morphology. Not only does it exhibit syncretism together with the ergative series, they are phonologically regular in having a coronal segment and near-agreement in manner to their ergative series counterparts.

${ }^{9} \mathrm{We}$ assume here that there is indeed regular syncretism across the paradigm despite some phonological differences. As we discussed in $\S 1$, restricting ourselves to the $=e l(2 / 3 \mathrm{pl}$ absolutive) case is a minor change. 
a. Structural description: a clitic $\mathrm{Cl}$ hosted by $\mathrm{C}$ specified as [+Participant]

b. Structural change: $\mathrm{Cl} \rightarrow$ [-Participant]

(48) Vocabulary Insertion for Non-past Subject Clitics, Absolutive Series

et $\leftrightarrow[\mathrm{C},+$ Absolutive, +Singular $]$

el $\leftrightarrow[\mathrm{C},+$ Absolutive, -Singular $]$

Note that by impoverishing the marked form of the Participant feature, we correctly derive the pattern that the syncretism is 3-to-2. We see across the paradigms that the labials $/ \mathrm{p} /-/ \mathrm{m} /$ are indicative of 3rd person. Hence the impoverished second person matches the feature specification of the third person, and they together contrast with the first person, which is still specified [+Author]. We must leave the featural specification and exponence of the exclusive and inclusive first person plurals as unanalyzed.

\subsection{Plural Fission}

Cupeño appears to exhibit a specific exponent for plurality, namely -m-, which is observed clearly in the past subject affixes and the object proclitics.

There are phonological complications to the data. Third person object proclitics alternate between $p i=$ and $=m i$ - suggestive of an OCP place effect, though we do have pem- as the $3 \mathrm{pl}$ subject affix. A similar effect is observed for the second and third person non-past subject clitics in the ergative series. This leaves us with the striking generalization that the absolutive non-past subject clitics are the only context where there appears to be no plausible instances of plurality marked by $/ \mathrm{m} /$. Again, we are led to conclude that the non-absolutive PN markers pattern together, and they have $-m$ - as an exponent for plurality.

Recall the definition of Morphological Fission, from Arregi \& Nevins (2012:132): it requires a category $\mathrm{C}$, and it repairs a restriction on the realization of two features $\mathrm{F}_{1}$ and $\mathrm{F}_{2}$ on the same terminal node. Thus we are led to posit two separate fission rules, one for $\mathrm{PN}$ affixes, and another for PN clitics. We interpret plural exponence as a restriction on realizing person and [-singular] on the same terminal node.

$$
\begin{aligned}
& \text { Affixal/Clitic Plural Fission: T/D, [Author], [-singular] } \\
& \text { Vocabulary Entry for Plural PN Morphemes: } \mathrm{m} \leftrightarrow[\text {-singular] }
\end{aligned}
$$

\subsection{Person Morphology}

After factoring out plural - $m$-, we are left with regular correspondences in person: first person $/ \mathrm{n} /$, first person plural /ch/, second person $/ \varnothing /$, and third person $/ \mathrm{p} /$.

We posit vocabulary entries for person, which are superceded in the absolutive series by entries which are specified for + Absolutive. Further, we propose a context-sensitive rule for the first-person plural form $/ \mathrm{ch} /$.

$$
\begin{aligned}
& \mathrm{n} \leftrightarrow[+ \text { Author }] \\
& \mathrm{ch} \leftrightarrow[\text { [+Author }] / \text { [-singular }] \\
& \varnothing \leftrightarrow[\text {-Author, +Participant }] \\
& \mathrm{p} \leftrightarrow[\text {-Author, -Participant }]
\end{aligned}
$$


This accounts for the ergative series of subject clitics as well: both second and third person clitics are specified as [-Author, -Participant] by Person Impoverishment, and hence the singular $2 / 3$ marker is $p$, and the plural is $p$ - $m$, which surfaces as $m .^{10}$

\subsection{T-conditioned Allomorphy}

Given the morphological fission rule established in the previous subsection, we may write vocabulary entries for the PN morphology. In the past, subject agreement is overt on $\mathrm{T}$ and person and number are realized separately.

The following structure is for the first person subject agreement in the past, after Plural Fission as applied. The terminal labeled $\mathrm{T}_{1}$ is realized with first person plural $/ \mathrm{ch} /$, and $\mathrm{T}_{2}$ is realized with plural /e/. Note that there is no competition in $\mathrm{T}_{2}$ involving person morphemes, as no vocabulary entry corresponds to a valued [Participant] feature without a valued [Author] feature.

First Person Subject Agreement

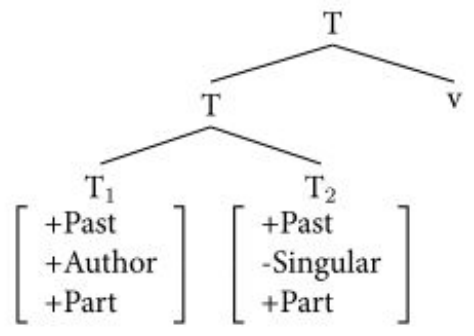

This analysis is incomplete in that it does not account for the realization of a vowel /e/ for subjects and /i/ for objects.

In the non-past, PN affixation on $\mathrm{T}$ is null. We take this to mean that the $\mathrm{T}$ terminal node is obliterated. Although we do not have a full analysis for the /e/ and /i/ vowels on the $\mathrm{PN}$ morphemes, we cite this as further evidence that $\mathrm{T}$ is being obliterated: the systematic absence of subject affixes on the verb in the non-past context is contrasted with the presence of a null second person morpheme + a vowel $e$ that realizes the $2 \mathrm{SG}$ subject in the past.

(53) Non-Past T Obliteration Rule

a. Structural description: A T terminal with [-Past]

b. Structural change: Delete T.

Let us look back at the proposed structure in (52). Even if Plural Fission were to occur before the obliteration operation, both T nodes would still bear the feature [-Past] and hence would be subject to $\mathrm{T}$ obliteration, and we correctly predict that no stray plural /-m/ will appear in the past.

In contrast to the subject agreement affix on the verb, the sensitivity to [Past] for the subject clitic in the clitic complex is purely syntactic: the absence of a syntactic host in the

\footnotetext{
${ }^{10} \mathrm{An}$ alternative, though more problematic, analysis is as follows: There is no phonological constraint like the OCP which bans the $p$ - $m$ sequence, as evidenced by forms like $3 \mathrm{pl}$ subject pem-. Instead, there is a number-conditioned split: the singular forms syncretize to the 3rd person /p/ morpheme, while the plural forms syncretize to the 2 nd person $/ \varnothing /$.
} 
past means there are no past subject clitics. Hence we only need vocabulary entries for the non-past subject clitics. This proceeds straightforwardly with the proviso that exceptional vocabulary entries are available for the absolutive-marked clitics.

Finally, the object clitics are derived in the same manner as the subject agreement affixes, with minor differences: (i) the vocabulary items are inserted on $\mathrm{D}$ terminals, not $\mathrm{T}$ terminals - not problematic as T nodes bear $\varphi$-features like D nodes through Agree; (ii) there is no obliteration of nodes due to [Past], so object clitics are overt in all tenses.

\section{Conclusion}

We have argued for an analysis of person-number morphology in Cupeño that proceeded as follows: subject and object clitics are assigned (dependent) case together with their source DP, and $\varphi$-feature agreement at $\mathrm{T}^{0}$ targets the subject DP. These syntactic operations occur regularly independent of tense. Tense-sensitive effects arise solely in the morphological component: clitics are not hosted by $\mathrm{C}^{0}[+$ past $]$ and $\mathrm{PN}$ affixation is realized as $\varnothing$ when $\mathrm{T}^{0}$ is [-past]. It is these two factors alternating with overt realizations that conspire to create an illusion of a tense-conditioned ergative split.

The simpler alternative is one that posits a structural difference sensitive to tense. We argued that a version of this approach that mirrors the aspect split analysis (cf. Coon (2010)) is untenable on empirical and conceptual grounds. Finally, we sketched a model of Cupeño PN morphology under the framework of Distributed Morphology.

We find the Cupeño data to be an illustrative example of how regular syntactic processes can be obscured by morphological conditions - Agree Link and Agree Copy, respectively, under the model of Distributed Morphology as argued for by Arregi \& Nevins (2012).

\section{References}

Arregi, Karlos, and Andrew Nevins. 2012. Morphotactics. Studies in Natural Language and Linguistic Theory. Springer.

BAKER, MARK. 1985. The Mirror Principle and morphosyntactic explanation. Linguistic Inquiry 16.373-415.

Baker, Mark, and Nadya Vinokurova. 2010. Two modalities of case assignment: Case in Sakha. Natural Language and Linguistic Theory 28.593-642.

Baker, Mark, and Nadya Vinokurova. 2012. Forms of predication in Sakha: Will the true lexical predicates please stand up. To appear in Canadian Journal of Linguistics.

Barragan, Luis M. 2003. Movement and allomorphy in the Cupeño verb construction. Studies in Uto-Aztecan, ed. by Luis Barragan and Jason Haugen, MIT Working Papers on Endangered and Less Familiar Languages, 141-161.

Bittner, Maria, and Kenneth Hale. 1996. The structural determination of Case and Agreement. Linguistic Inquiry 27.1-68. 
Bobaljik, Jonathan. 2008. Where's phi? Agreement as a post-syntactic operation. Phitheory: Phi features across interfaces and modules, ed. by Daniel Habour, David Adger, and Susana Béjar, 295-328. Oxford University Press.

Chomsky, NoAm. 1995. The Minimalist Program. MIT Press.

Chomsky, NoAm. 2000. Minimalist inquiries: The framework. Step by step: Essays on minimalist syntax in honor of Howard Lasnik, ed. by Roger Martin, David Michaels, and Juan Uriagereka, 83-155. MIT Press.

Chung, Sandra, and James McCloskey. 1987. Government, barriers, and small clauses. Linguistic Inquiry 18.173-237.

Coon, Jessica. 2010. Complementation in Chol (Mayan): A theory of split ergativity dissertation.

Coon, Jessica, and Omer Preminger. 2012. Towards a unified account of person splits. Proceedings of the 29th West Coast Conference on Formal Linguistics (WCCFL 29), ed. by Jaehoon Choi, Alan Houge, Jessamyn Schertz, Jeff Punske, Deniz Tat, and Alex Trueman, 310-318. Cascadilla Press.

Deal, Amy Rose. 2013. Ergativity. To appear in International Handbook on Syntactic Contemporary Research, 2nd edition.

Dixon, R. M. W. 1994. Ergativity. Cambridge University Press.

Embick, David, and Rolf Noyer. 2001. Movement operations after syntax. Linguistic Inquiry 32.555-595.

Harley, Heidi. 2004. Merge, conflation and head movement: the first sister principle revisited. Proceedings of nels 34. GSLA.

HARLey, HeIDI. 2007. Distributed Morphology lecture notes.

Hill, Jane H. 2005. A grammar of Cupeño. University of California Press.

Kayne, Richard. 1975. French syntax: The transformational cycle. MIT Press.

Laka, Itziar. 2006. Deriving split-ergativity in the progressive: the case of Basque. Ergativity: Emerging issues, ed. by Alana Johns, Diane Massam, and Juvenal Ndayiragije, Studies in Natural Language and Linguistic Theory. Springer.

Legate, Julie Anne. 2008. Morphological and abstract Case. Linguistic Inquiry 39.55101.

Mahajan, Anoop. 1990. The a/a-bar distinction and movement theory dissertation.

Marantz, Alec. 1991. Case and licensing. vol. Proceedings of the 8th Eastern States Conference on Linguistics, 234-253. 
Matushansky, ORA. 2006. Head-movement in linguistic theory. Linguistic Inquiry 37.69109.

MCCloskey, James. 1997. Subjecthood and subject positions. Elements of grammar, ed. by L. Haegeman. Kluwer.

Ouali, Hamid. 2008. On C-to-T phi-feature transfer: The nature of Agreement and AntiAgreement in Berber. Agreement restrictions, ed. by Roberta D'Alessandro, Gunnar Hrafn Hrafnbjargarson, and Susann Fischer, 159-180. Mouton de Gruyter.

Pesetsky, David, and Esther Torrego. 2001. T-to-C movement: causes and consequences. Ken Hale: A life in language, ed. by Michael Kenstowicz. MIT Press.

Preminger, Omer. 2011a. Agreement as a fallible operation dissertation.

Preminger, Omer. 2011b. Asymmetries between person and number in syntax: A commentary on Baker's SCOPA. Natural Language and Linguistic Theory 29.917-937.

Salanova, AndrÉs Pablo. 2007. Nominalizations and aspect dissertation.

Torrego, Esther. 1992. Case and agreement structure. Manuscript, UMass Boston.

TraVis, LisA. 1984. Parameters and effects on word order variation dissertation.

URIAGereKa, JuAn. 1995. Aspects of the syntax of clitic placement in western Romance. Linguistic Inquiry 25.79-123.

Woolford, Ellen. 1997. Four-way case systems: Ergative, nominative, objective and accusative. Natural Language and Linguistic Theory 15.181-227.

YiP, Moira; Joan Maling; and Ray JaCKendoff. 1987. Case in tiers. Language $63.217-250$. 